\title{
Transcriptional and translational regulation of the expression of the major outer surface proteins in Lyme disease Borrelia strains
}

\author{
Maria Jonsson and Sven Bergstrom
}

Author for correspondence: Sven Bergström. Tel: +4690 176726. Fax: +4690772630.

Department of

Microbiology, University of Umeá, S-901 87 Umeá, Sweden

\begin{abstract}
The major outer surface proteins of Lyme disease spirochaetes are differentially expressed in different isolates. Borrelia afzelii strain F1 expresses none, or very low amounts, of the OspA and OspB proteins. To elucidate the mechanisms that control the expression of these abundant surface proteins the ospAB operon of B. afzelif F1 was cloned, sequenced and compared to the previously sequenced ospAB operon of B. afzelif ACAI and Borrelia burgdorferi B31. The two B. afzelif strains showed almost $100 \%$ identity at the DNA level, although Coomassie-stained gels and Western blot analyses showed significant variation in the Osp protein content. Transcriptional analysis revealed that the amount of OspAB mRNA produced in $B$. afzelif F1 varies more than the amount of protein, suggesting that the expression of OspA and OspB proteins is regulated at both the transcriptional and the translational level. Furthermore, the inverse relationship between the transcription of OSpC and the ospAB operon could indicate coregulation of these separately encoded operons.
\end{abstract}

Keywords: Borrelia afzelii, Borrelia burgdorferi, outer surface proteins, OspA, OspB and OspC

\section{INTRODUCTION}

The multisystem disorder Lyme disease can be caused by three spirochaetal species, Borrelia afzelii, Borrelia burgdorferi and Borrelia garinii (Burgdorfer et al., 1982; Baranton et al., 1992; Canica et al., 1993). Lyme disease is characterized by a variety of different symptoms, which can develop into a chronic syndrome. Several reports indicate that the spirochaetes can survive for a prolonged period of time in the human host. They have been isolated from an acrodermatitis chronica atrophicans (ACA) patient 10 years after the onset of the disease (Åsbrink \& Hovmark, 1985). It has further been reported that some patients with Lyme disease developed new antibodies a year or more after the initial infection (Craft et al., 1986). This indicates that the borreliae may escape the human immune defence system by some kind of antigenic variation or modulation of expression of one or several outer surface molecules. However, this is contradicted by recent studies of Borrelia infections in mice, which indicate that the spirochaetes are antigenically stable, and may

Abbreviations: mAb, monoclonal antibody; $A C A$, acrodermatitis chronica atrophicans. survive by sequestration in parts of the body which are inaccessible to the immune system (Barthold, 1993; Barthold \& Bockenstedt, 1993; Jonsson et al., 1995).

Most Lyme disease Borrelia strains express two major outer surface lipoproteins, OspA and OspB. In the American B. burgdorferi reference strain B31, the molecular masses of these proteins are 31 and $34 \mathrm{kDa}$, respectively (Howe et al., 1985; Bergström et al., 1989). The OspA and OspB proteins from different species and isolates vary both in molecular mass and immunological reactivity with different monoclonal antibodies (mAbs) (Barbour, 1984; Barbour et al., 1985; Barbour \& Schrumpf, 1986; Wilske et al., 1988b; Bundoc \& Barbour, 1989). Some strains appear to lack the expression of both OspA and OspB, but instead express a smaller $21-25 \mathrm{kDa}$ protein, OspC. In addition, a fourth outer surface protein, the $28 \mathrm{kDa}$ OspD, has been reported. This protein was first shown to be expressed only in low passage, virulent strains (Norris et al., 1992). However, more recent data contradict the influence of passages on expression of the OspD protein (Marconi et al., 1994) The OspA, OspB and OspC proteins are all highly immunogenic. Despite this immunogenicity, only antibodies directed against OspC, and not against the OspA and OspB proteins, are usually 
found in sera from patients with early Lyme disease (Wilske et al., 1986, 1988a). This indicates differences in the expression or exposure of the proteins within the human host.

The $\operatorname{ssp} A$ and $\operatorname{ss} p B$ genes are located in one operon, separated by a few bases, and transcribed as one transcriptional unit from a linear plasmid about $50 \mathrm{~kb}$ in size (Howe et al., 1986; Barbour \& Garon, 1987; Bergström et al., 1989; Jonsson et al., 1992). The ospC gene is not part of the osp $A B$ operon, but is encoded on one of the small circular plasmids (Marconi et al., 1993; Sadziene et al., 1993). The expression of the OspA and OspB proteins and their regulation have been studied. Eiffert et al. (1992) published the nucleotide sequence of the os $p A B$ operon from a $B$. burgdorferi strain that expressed OspA but not OspB. Analysis of the sequence revealed that the ospB gene could not be expressed because it lacked a start codon in the correct reading frame. This was probably due to a frameshift mutation caused by a deletion. Rosa $e t$ al. (1992) have shown that new osp loci can be formed in vitro by homologous recombination and point mutations. This can result in the loss of expression of the OspB protein, or the loss of both OspA and OspB in favour of the expression of a chimeric OspA/OspB protein (Rosa et al., 1992). Moreover, Margolis \& Rosa (1993) have published a study of a $B$. burgdorferi strain which does not express the OspA or OspB proteins, even though it contains an intact $\operatorname{cs} p A B$ operon capable of expression. In that study, it was suggested that the expression of the OspA and B proteins is regulated at the transcriptional level, as no transcript was detected.

The regulation of OspC expression has also been studied. B. burgdorferi B31 usually lacks the expression of OspC. However, mutant clones of $\mathrm{B} 31$ which had lost a $16 \mathrm{~kb}$ linear plasmid resumed expression of the OspC protein. This, together with the finding that only strains lacking DNA homologous to the $16 \mathrm{~kb}$ plasmid express the protein, suggests that $\mathrm{OspC}$ is negatively regulated by a factor encoded by this plasmid (Hinnebusch \& Barbour, 1992; Sadziene et al., 1993). This is different from the situation found in another study, where OspC-expressing clones were obtained from a non-expressing isolate of $B$. burgdorferi $\mathrm{Pka} 2$ upon culture on solid media (Wilske et al., 1993). This could, however, be due to loss of the $16 \mathrm{~kb}$ plasmid during subsequent cultivation in liquid medium.

In the present work, we studied the expression of Osp proteins of the Swedish tick isolate B. afrelii F1. This strain was previously reported to lack both OspA and OspB in favour of the smaller OspC protein (Barbour \& Schrumpf, 1986; Shoberg et al., 1994). To gain understanding of the regulatory mechanisms involved in the variable expression of the Osp proteins, we studied the expression of these proteins, and cloned and sequenced the $B$. afzelii $\mathrm{F} 1$ osp $A B$ operon. By comparison with the osp $A B$ operon of $B$. afzelii ACAI we hoped to obtain an indication as to which mechanisms are involved in the regulation of outer surface protein expression. We demonstrated that the nucleotide sequence of the $\cos p A B$ operon of B. afzelii strains F1 and ACAI are almost identical, the transcripts are similar in size and the osp $A B$ operons in both strains use the same transcriptional starting point. The amount of transcript detected in different F1 populations varies, indicating that the level of $\mathrm{mRNA}$ produced can be modulated. The relative amount of osp $A B$ transcript produced fluctuates more than the amount of protein produced, suggesting that the expression of OspA and $\mathrm{OspB}$ may be regulated not only at the transcriptional level, but also at the translational level. Moreover, there is an inverse relationship between the transcription of the ospC gene and the osp $A B$ operon.

\section{METHODS}

Bacterial strains. The Borrelia strains used in this study were the North American B. burgdorferi reference strain B31 (ATCC 35210 ), the B31 mutant B313, which lacks the $49 \mathrm{~kb}$ linear plasmid and thereby the whole $\operatorname{osp} A B$ operon (Sadziene et al., 1993), and the two Swedish B. afzelii isolates, ACAI (Åsbrink et al., 1984) and F1 (Barbour \& Schrumpf, 1986). The borreliae used were all high passage strains. Different cultures of $F 1$ are denoted $\mathrm{F} 1 \mathrm{a} 1$ etc., where $\mathrm{F} 1 \mathrm{a} 2$ is inoculated from culture $\mathrm{F} 1 \mathrm{a} 1$ and so on. F1a, b and $\mathrm{c}$ are lineages inoculated from different frozen cultures. B31 and F1 are both tick isolates, while ACAI was cultured from the biopsy of a patient with ACA. The Borrelia strains were cultivated in BSKII medium as previously described (Barbour, 1984). The Escberichia coli strain DH5 $\alpha$ (BRL) was used for the propagation of recombinant plasmids.

Preparation of an anti-OspA rabbit serum. Rabbit antibodies were raised by repeated subcutaneous injections of $85 \mu \mathrm{g}$ recombinant ACAI OspA protein (kindly provided by Dr M. Strömqvist, Symbicom, Umeå, Sweden) with Freund's incomplete adjuvant. Serum was collected at various intervals after immunization, and the titre of OspA-specific antibodies was determined by Western blotting (data not shown).

Extraction of Borrelia proteins, SDSPAGE and Western blotting. Whole cell lysates were obtained by sonication of approximately $10^{10}$ Borrelia cells, and the amount of protein was determined as previously described (Jonsson et al., 1992). Proteins were separated on SDS-PAGE gels essentially as described previously (Barbour $\mathrm{et}$ al., 1985) in 12.5\% acrylamide separation gels and $4 \%$ acrylamide stacking gels. The gels were either fixed and stained with Coomassie brilliant blue (Sigma), or transferred to Fluorotrans transfer membranes (Colly, Stockholm, Sweden) by electroblotting as described previously (Jonsson et al., 1992). In SDS-PAGE gels processed for immunoblotting, $5 \mu \mathrm{g}$ protein of whole cell lysate was used in each lane, and $50 \mu \mathrm{g}$ of total protein was used in gels for visualization by staining. The molecular mass standards included proteins in the size range of $14 \cdot 4-94 \mathrm{kDa}$ (Pharmacia).

The $\mathrm{mAbs}$ used in these studies were the genus-specific antiflagellin mAb H9724 (Barbour et al., 1985), anti-OspA mAb 184.1 (a kind gift from Dr B. Luft, Stony Brook, New York, $\mathrm{NY}$, USA), and the anti-OspB $\mathrm{mAb} 84 \mathrm{C}$ (kindly provided by $\mathrm{Dr}$ D. D. Thomas, San Antonio, TX, USA). The preparation of polyclonal anti-OspA serum is described above, and the polyclonal anti-Osp $C$ serum was a kind gift from Dr A. G. Barbour, San Antonio, TX, USA. The Western blot filters were blocked by incubation with $5 \%(\mathrm{w} / \mathrm{v})$ non-fat milk powder in PBS ( $0.15 \mathrm{M}$ sodium chloride, $0.05 \mathrm{M}$ sodium phosphate, $\mathrm{pH} 7.4$ ) for $2 \mathrm{~h}$ or overnight. The filters were then incubated with the antibodies diluted in $2.5 \%(\mathrm{v} / \mathrm{v})$ milk/PBS $(1: 40, \mathrm{v} / \mathrm{v}$, for $\mathrm{mAb} H 9724 ; 1: 25, \mathrm{v} / \mathrm{v}$, for $\mathrm{mAb} 184.1 ; 1: 1000, \mathrm{v} / \mathrm{v}$, for $\mathrm{mAb} 84 \mathrm{C}$ and polyclonal anti-OspA serum; and $1: 200, \mathrm{v} / \mathrm{v}$, 


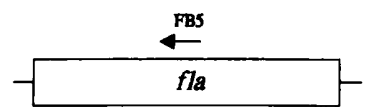

FBS: 5-AAC AGC TGA AGA GCT TGG AA-3

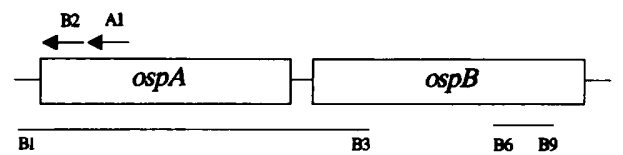

Fig. 1. Genetic map showing the sequence and location of the oligonucleotides used in Northern blots, primer extension and PCR amplification. The boxes represent the fla, ospC, ospA and osp $B$ genes, the arrows indicate the location and direction of the oligonucleotides and the solid lines below the ospAB genes represent PCR fragments used as probes for Southern blotting.

for polyclonal anti-OspC serum) for $1 \mathrm{~h}$ at room temperature, washed four times for 5 min each with PBS $/ 0.05 \%$ Tween 20 , and then incubated with the appropriate secondary antibody for $1 \mathrm{~h}$ at room temperature. Detection of binding of $\mathrm{mAb} 184.1$ was performed using horseradish peroxidase-linked secondary antibodies and the Amersham ECL Western blotting analysis system as recommended by the manufacturer. For the polyclonal anti-OspA and anti-OspC sera, and for mAbs $\mathrm{H} 9724$ and $84 \mathrm{C}$, ${ }^{125} \mathrm{I}$-labelled species-specific $\mathrm{F}\left(\mathrm{ab}^{\prime}\right)_{2}$ (Amersham) were used at a concentration of $1 \mathrm{mCi}(37 \mathrm{MBq}) \mathrm{ml}^{-1} \mathrm{PBS} / 0.05 \%$ Tween 20. The filters were washed once for $15 \mathrm{~min}$, four times for $5 \mathrm{~min}$ each in PBS $/ 0.05 \%$ Tween 20 , rinsed in PBS and then air-dried prior to autoradiography.

Electron microscopy. Cells were fixed with $4 \%$ paraformaldehyde $/ 0.3 \%$ glutaraldehyde in PBS for $1 \mathrm{~h}$, centrifuged and postfixed in $4 \%$ paraformaldehyde overnight. Small pieces of the pellet were infused with $20 \%$ polyvinylpyrolidine in $2.3 \mathrm{M}$ sucrose for $2 \mathrm{~h}$ and subsequently frozen in liquid nitrogen. Ultrathin sections were cut and mounted on formvar-coated nickel grids. For the antibody reactions, the grids were floated on drops of: (a) $0.12 \%$ glycine-PBS/foetal calf serum (FCS) for $10 \mathrm{~min}$, (b) affinity-purified (Sambrook et al., 1989) polyclonal anti-OspA or anti-OspC sera diluted $1: 10, \mathrm{v} / \mathrm{v}$, in PBS/FCS for $1 \mathrm{~h}$, (c) PBS/FCS for $30 \mathrm{~min}$, (d) goat anti-rabbit immunogold (GAR 10) for $1 \mathrm{~h}$, (e) PBS for $30 \mathrm{~min}$. The grids were then rinsed in distilled water and embedded in methylcellulose before microscopic analysis.

Quantification of proteins. Quantification of the Western blot signals was performed using a PhosphorImager (Molecular Dynamics). The flagellin signal was used as an internal standard to normalize for the amount of protein loaded in each lane. After this normalization, the amount of OspA, OspB and OspC was expressed relative to the highest value of the respective protein.

DNA techniques. Restriction enzymes, T4 DNA ligase (BioLabs, Finnzymes OY) and the T7 sequencing kit (Pharmacia) were used as recommended by the manufacturers. Borrelia DNA was prepared as previously described (Barbour, 1988; Barbour \& Garon, 1987; Howe et al., 1985).

Construction and screening of pUC18 plasmid gene libraries. B. afzelii F1 DNA was completely digested with HindIII, separated on a $0 \cdot 7 \%$ agarose gel and transferred to a Nylon filter (Hybond-N, Amersham) by capillary blotting overnight. The filter was hybridized with two $\left[\alpha^{32} \mathrm{P}\right] \mathrm{dATP}$ oligolabelled osp-specific fragments. One fragment, 1151 bp long, covers the whole $\operatorname{csp} A$ gene and the beginning of $\operatorname{cs} p B$, while the other, $254 \mathrm{bp}$ long, was synthesized from the middle of the $o s p B$ gene. The fragments were obtained by PCR amplification of $B$. afzelii F1 DNA using the primer pairs B1-B3 and B6-B9 (Fig. 1), and the same reaction conditions as described previously (Jonsson $e t$ al., 1992). The areas corresponding to the signals were cut out from a $0.7 \%$ low melting point agarose gel (LMP Sea Plaque GTG, FMC, In vitro AB) DNA was extracted using Magic PCR Preps DNA Purification System (SDS Promega), ligated into a HindIII-digested pUC18 plasmid vector, and then transformed into competent $E$. coli $\mathrm{DH} 5 \alpha$. To screen for clones containing the osp genes, colony hybridization was performed according to standard methods (Ausubel et al., 1992), both with the mixed PCR probe and the osp $A$-specific oligonucleotide $\mathrm{B} 2$.

Nucleotide sequence analysis. The clones containing the os $p$ genes were sequenced by the Sanger dideoxy sequencing method (Sanger et al., 1977) using vector-specific and internal osp-specific oligonucleotides as primers (Jonsson et al., 1992). The sequences obtained were assembled using the GENEUS (Harr et al., 1986) software for VAX computers (Digital Equipment).

RNA techniques. RNA was extracted from late exponential phase Borrelia cultures, i.e. dense cultures with motile spirochaetes, using hot phenol extraction (von Gabain et al., 1983). Total RNA $(10 \mu \mathrm{g})$ was loaded in each lane and separated on a $1 \%(\mathrm{v} / \mathrm{v})$ formaldehyde agarose gel at $100 \mathrm{~V}$ for $6 \mathrm{~h}$. The gel was neutralized in $1 \times$ HEPES (Ausubel et al., 1992), and the RNA was transferred to a Nylon filter (Hybond-N, Amersham) by capillary blotting overnight. The filter was hybridized at high stringency with $\left[\gamma_{-}{ }^{32} \mathrm{P}\right] \mathrm{ATP}$ end-labelled oligonucleotides. B2 was used for $\operatorname{csp} A$, FB5 was used for $f l a$, and C3 for $\operatorname{csp} C$ (Fig. 1). Quantification of the Northern blot signals was performed as described above for Western blot quantification.

Transcriptional analysis was performed on total RNA prepared as described above. Total RNA $(5 \mu \mathrm{g})$ was dried together with $0.5 \mathrm{pmol}\left[\gamma_{-}{ }^{32} \mathrm{P}\right] \mathrm{ATP}$ end-labelled oligonucleotide A1 (Fig. 1), and then dissolved in $8 \mu \mathrm{l}$ annealing buffer $(50 \mathrm{mM}$ Tris/ $\mathrm{HCl}$, $\mathrm{pH} 8.3,60 \mathrm{mM} \mathrm{NaCl}$ and $10 \mathrm{mM}$ DTT). The mixture was denatured at $80^{\circ} \mathrm{C}$ for $5 \mathrm{~min}$, and then immediately transferred onto ice for $5 \mathrm{~min}$. Eight $\mu \mathrm{l}$ extension buffer $(25 \mathrm{mM}$ Tris $/ \mathrm{HCl}$, $\mathrm{pH} 8.3,30 \mathrm{mM} \mathrm{NaCl}, 15 \mathrm{mM} \mathrm{MgCl}{ }_{2}$ ), $1.25 \mathrm{mM} \mathrm{DTT}, 1 \mathrm{mM}$ of each dNTP, and 7 units of avian myeloblastosis virus reverse transcriptase (Boehringer Mannheim) were added. The samples were incubated at $42^{\circ} \mathrm{C}$ for $1 \mathrm{~h}$. Formamide sample buffer $(16 \mu \mathrm{l})$ from the T7 sequencing kit (Pharmacia) was added. Samples $(2 \mu \mathrm{l})$ were loaded following denaturation at $80^{\circ} \mathrm{C}$ for $3 \mathrm{~min}$. Only full-length extension product was synthesized, and the size of the transcript was compared with that of a regular Sanger dideoxy $\left[{ }^{35} \mathrm{~S}\right] \mathrm{dATP} \alpha \mathrm{S}$ DNA sequence on plasmid $\mathrm{pM} J 08$ for strain F1, or pMJ05 for strain ACAI (Jonsson et al., 1992) with the same oligonucleotide primer.

Expression of OspA in E. coli. The plasmid pM J05 was digested with HindIII and the $1.5 \mathrm{~kb}$ fragment containing the osp $A$ gene was isolated and ligated into pUC18. A clone, pM J06, having the $\operatorname{csp} A$ gene in the opposite direction to the lac $Z$ gene in pUC18, was isolated. E. coli DH5 $\alpha$ containing pUC18, pMJ05, pM J06 and pM J08 was grown in L-broth and harvested at a cell density of $4 \times 10^{8}$ cells $\mathrm{ml}^{-1}$ by centrifugation. Western blotting with the polyclonal anti-OspA rabbit serum and secondary peroxidase-labelled anti-rabbit serum was performed as described above. 


\section{RESULTS}

\section{Biochemical and immunochemical characterization of the outer surface proteins}

Whole cell protein extracts prepared from $B$. burgdorferi $\mathrm{B} 31, B$. afzelii $A C A I$ and different $B$. afzelii $\mathrm{F} 1$ cultures were separated on a $12.5 \%$ SDS polyacrylamide gel (Fig. 2). Preparations of strain $B 31$ contained a $31 \mathrm{kDa}$ OspA and a $33.5 \mathrm{kDa}$ OspB (Fig. 2). B. af zelii ACAI expressed an OspA of about $32.5 \mathrm{kDa}$ and a $34.5 \mathrm{kDa} O \operatorname{OspB}$. In $B$. afzelii $\mathrm{F} 1$, the dominant band was a $25 \mathrm{kDa}$ protein. However, bands of 32 and $35 \mathrm{kDa}$ were also seen, indicating low but detectable expression of the OspA and OspB proteins in this strain.

Western blot analysis was performed to confirm the expression of OspA, OspB and OspC. Two mAbs, 184.1 and $84 \mathrm{C}$, directed against the OspA and OspB proteins, respectively, and polyclonal anti-OspA and anti-OspC sera, were used. 184.1 is an anti-OspA mAb (Jiang et al., 1990 ) which reacts only with the B31 and ACAI proteins, and not with those of the F1 strain (Fig. 3a). The polyclonal anti-OspA serum raised against the B. afzelii strain ACAI reacts with all three strains. The sequence heterogeneity between the OspA of B. burgdorferi sensu stricto and the $B$. afzelii strain is probably the reason for the apparently weaker reactivity to the $B$. burgdorferi sensu stricto $\mathrm{B} 31$ OspA protein (Fig. $3 \mathrm{~b}$ ). $\mathrm{mAb} 84 \mathrm{C}$ has been shown to react with OspB of most Lyme disease Borrelia strains that have been tested (Shoberg et al., 1994) and reacted with all three strains used in this study (Fig. 3c). Western blot analysis using the polyclonal anti-OspA

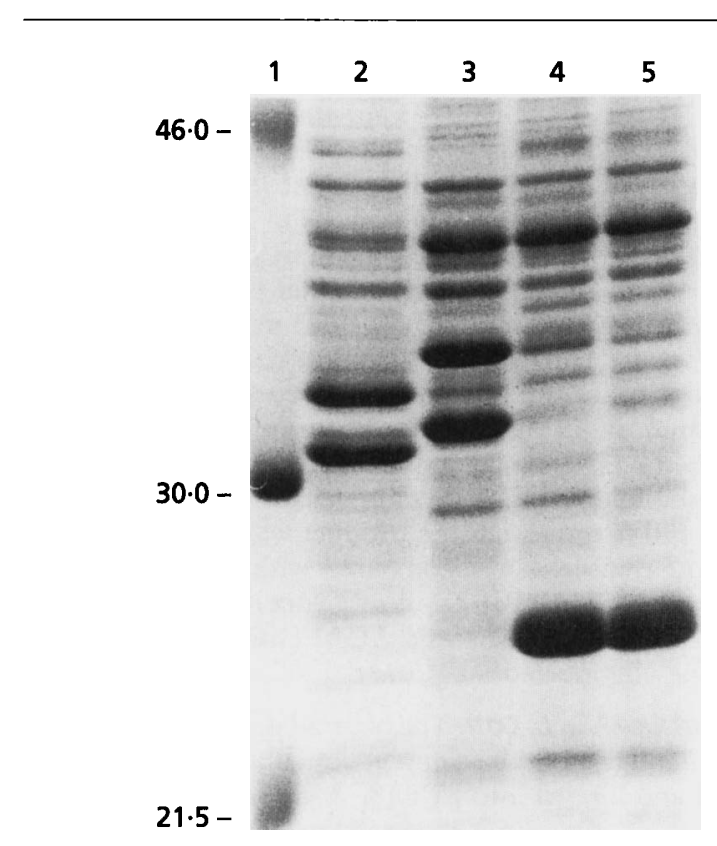

Fig. 2. Whole cell lysates of Borrelia strains separated on a $12.5 \%$ SDS polyacrylamide gel and stained with Coomassie brilliant blue. Lanes: 2, B. burgdorferi B31; 3, B. afzelii ACAl; 4, B. afzelii F1C1; 5, B. afzelii F1b1. Lane 1 contains molecular mass standards labelled in $\mathrm{kDa}$.

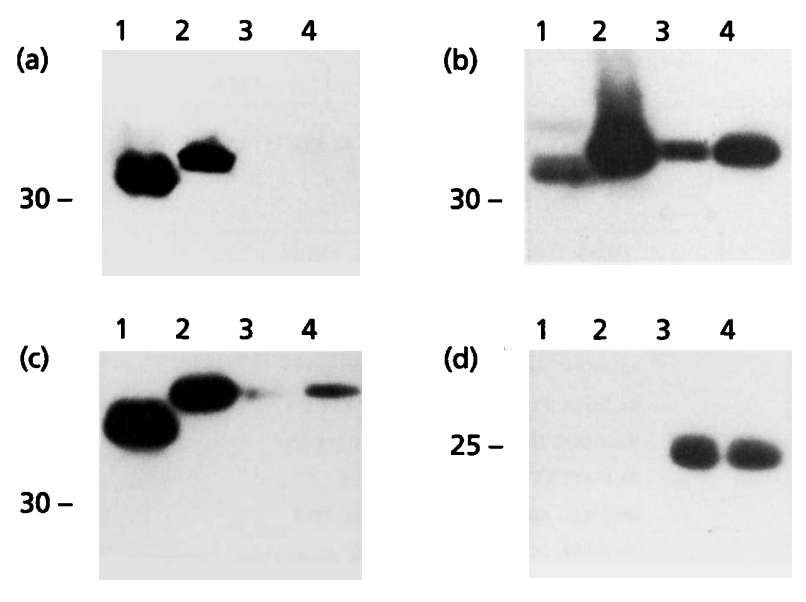

Fig. 3. Western blot analysis of $10 \mu \mathrm{g}$ whole cell lysate from Borrelia strains separated on $12.5 \%$ SDS polyacrylamide gels and treated with (a) OspA-specific mAb 184.1, (b) polyclonal anti-OspA serum, (c) OspB-specific mAb $84 C$ or (d) polyclonal anti-OspC serum. Lanes: 1, B. burgdorferi B31; 2, B. afzelii $\mathrm{ACAl} ; 3$, B. afzelii $\mathrm{F} 1 \mathrm{C1} ; 4$, B. afzelii $\mathrm{F} 1 \mathrm{~b} 1$. In (a) the antibodies were detected with the ECL Western blotting detection system and in (b), (c) and (d) with iodinated secondary $F\left(a b^{\prime}\right)_{2}$ fragments. Molecular mass standards are shown on the left in $\mathrm{kDa}$.

serum shows that the F1 strain expresses the OspA protein, but at a much lower level than strains B31 and ACAI (Fig. 3b). There is only $77 \%$ identity at the amino acid level of the OspA protein in B31 compared to both ACAI and F1 (Jonsson et al., 1992; this study). The heterogeneity between B31 and F1 in combination with the low level of expression could explain the lack of reactivity of $\mathrm{mAb} 184.1$ to the OspA of strain F1 (Fig. $3 a)$. No signal could be detected with the OspAB-less mutant $B$. burgdorferi $\mathrm{B} 313$, demonstrating the specificity of the polyclonal serum (data not shown). A slight cross reactivity to the $\mathrm{B} 31 \mathrm{OspB}$ protein could be seen, but not to the ACAI or F1 OspB proteins. A Western blot experiment was also performed with a polyclonal OspCspecific antiserum. This reacted strongly with a protein of about $25 \mathrm{kDa}$ in the $\mathrm{F} 1$ strains, and very weakly with a protein of similar size in the ACAI strain (Fig. 3d).

\section{Quantification of the outer surface proteins}

The relative amounts of OspA, OspB and OspC proteins in ACAI and three different cultures of $\mathrm{F} 1$ are shown in Fig. 4, together with the relative amount of $\operatorname{cs} p A B$ transcript. In ACAI the OspA and OspB proteins were expressed at a high level. In the three preparations of $\mathrm{F} 1$ lysates shown, the amounts of OspA and OspB protein differ, but the level is much lower than in ACAI. In all three lysates, less OspB than OspA protein was made. The signals corresponding to the OspB proteins in all F1 strains were above the detection limit, but, as the OspB signal of strain ACAI was much stronger, the relative amounts of OspB in the F1 cultures was very low (Fig. 4). The opposite was observed with the OspC protein. The 


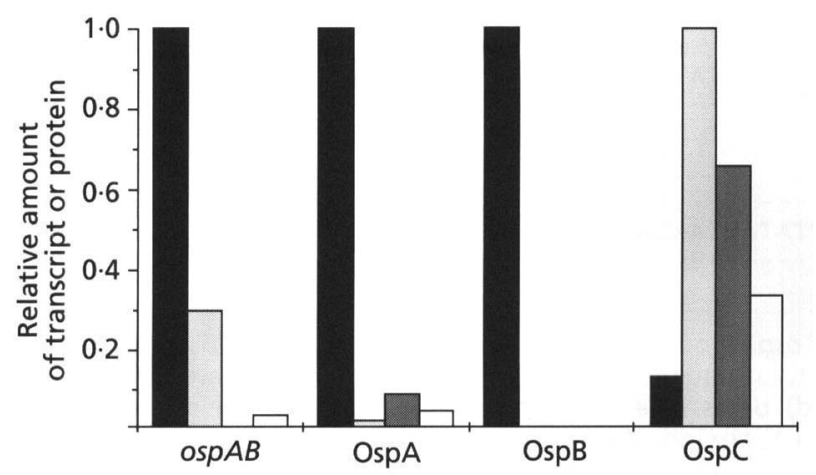

Fig. 4. The relative amounts of ospAB transcript and of OspA, OspB and OspC proteins in B. afzelii ACAI ( $\square$ ) and B. afzelii

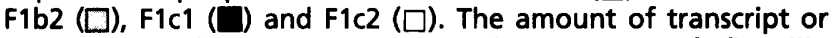
protein was first normalized to the amount of flagellin transcript or protein in the preparation and then expressed relative to the highest value of the respective transcript or protein.

OspC signal from strain ACAI was just on the limit of detection, but the polyclonal anti-OspC serum gave a weaker signal compared to the other Osp antibodies, resulting in an apparently higher relative amount of OspC protein in strain ACAI. Less material was applied on the protein gel from culture F1c2, increasing the statistical error of the Osp protein signals.

\section{Electron microscopy}

Representative photomicrographs of the dramatic differences in protein expression in B. afzelii ACAI and $B$. afzelii $\mathrm{F} 1$ are shown in Fig. 5. Considerable OspA, but very little $\mathrm{OspC}$ was found on the surface of strain ACAI. In contrast, OspC was clearly an abundantly expressed outer surface protein of strain F1.

\section{Genetic characterization of the osp operon}

Separation of total DNA prepared from Borrelia strains B31, ACAI and F1 by pulsed field gel electrophoresis showed that the DNA content of F1 is very similar to that of ACAI, except for the existence of one small $(25 \mathrm{~kb})$, additional plasmid in F1 (data not shown). Southern blot hybridization using an OspA-specific oligonucleotide, showed that $\mathrm{F} 1$ has its $\operatorname{cs} p A B$ operon localized in a $50 \mathrm{~kb}$ linear plasmid, similar to that in B31 and ACAI (Jonsson et al., 1992).

Southern blot hybridization of HindIII-digested B. afzelii F1 DNA using two PCR fragments covering both the beginning of the $\operatorname{csp} A B$ operon and the middle of the $\operatorname{csp} B$ gene as probes, was performed. Two hybridization signals were observed, indicating that there is a HindIII site in the $B$. afzelii $\mathrm{F} 1$ osp $A B$ operon. The signals correspond to fragments of about 0.9 and $1.5 \mathrm{~kb}$. Other restriction enzymes with sites in suitable cloning vectors were tested, but none gave a single fragment. The 0.9 and $1.5 \mathrm{~kb}$ (a)

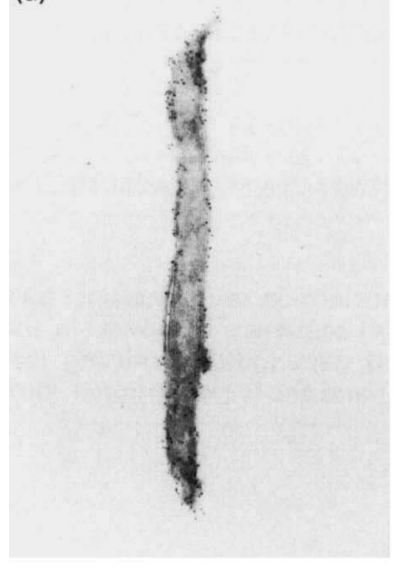

(c)

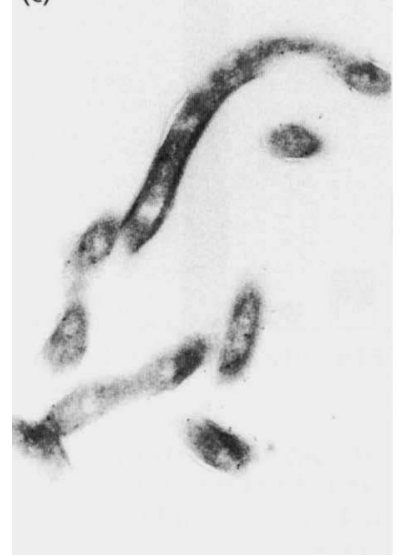

(b)

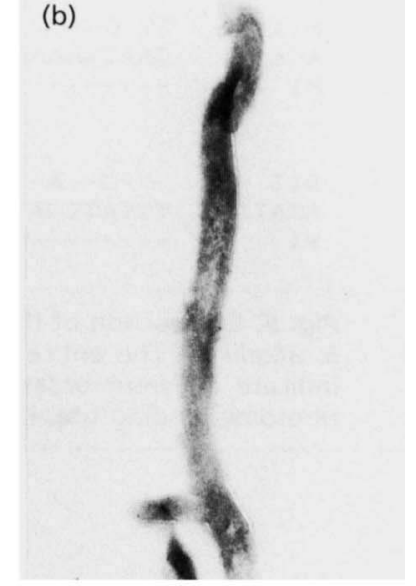

(d)

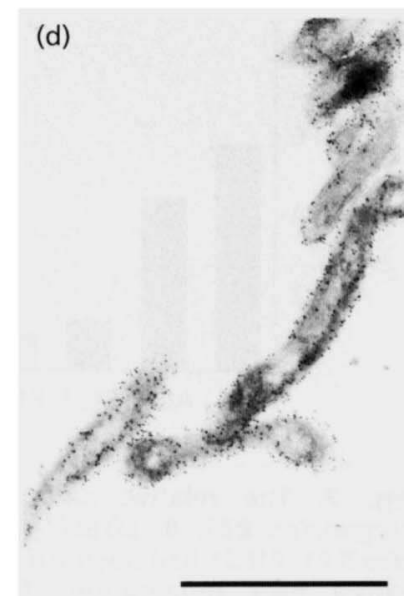

Fig. 5. Electron micrographs of B. afzelii ACAI (a, c) and B. afzelii $\mathrm{F} 1(\mathrm{~b}, \mathrm{~d})$ treated with affinity-purified polyclonal anti$\operatorname{OspA}(a, b)$ or anti-OspC (c, d) sera. Bar, $1 \mu \mathrm{m}$.

fragments were isolated and ligated into the HindIII site of pUC18. The whole DNA sequence was determined using vector-encoded and internal osp-specific oligonucleotides as primers. A comparison of the $\cos p A$ and osp $B$ nucleotide sequences of strain $F 1$ with the previously published sequences from $B$. afzelii $A C A I$ and $B$. burgdorferi $\mathrm{B} 31$ showed that the $\mathrm{F} 1$ sequence is almost identical to the ACAI sequence (data not shown). Only two base pairs differ within the coding region. There is an A to $\mathrm{G}$ transition in position 264 , i.e. at the beginning of $\operatorname{osp} A$, giving a glycine instead of a glutamate in the putative amino acid sequence. It is possible that this amino acid is part of the epitope for $\mathrm{mAb} 184.1$, as the F1 OspA is not recognized by this $\mathrm{mAb}$. The second difference is an $A$ to $C$ exchange at the end of $\operatorname{ssp} B$, in position 1419. This change gives a leucine instead of an isoleucine. Furthermore, in the region upstream of the -35 hexanucleotide of the promoter, strain ACAI has a stretch of ten Ts, whereas strain F1 has only nine Ts in this area (Fig. 6).

To determine the transcriptional start site, a primer extension analysis on RNA from both ACAI and F1 was 
B31

ACAI

F1

BCAI

F1

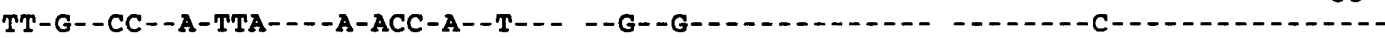
CAATAAAAAATCCATATTAGATTTATACCTAATTTAAAATTATTATCATTTTATTTTTTTTTTAATTTTCTATTTGTTA

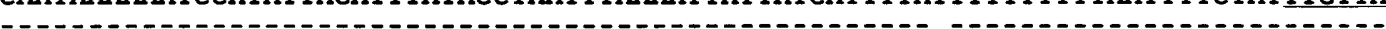

$-10$

$+1$

RBS

ospA $\rightarrow$

Fig. 6. Comparison of the nucleotide sequence upstream of the ospAB operon in $B$. burgdorferi B31, B. afzelii ACAI and $B$. afzelii $\mathrm{F1}$. The entire ACAl sequence is shown. In the other two sequences, hyphens indicate identical bases, letters indicate different bases and gaps indicate missing (or inserted) bases. The -35 and -10 regions of the promoter, ribosome-binding sites (RBS) and the transcriptional start point $(+1)$ are indicated.

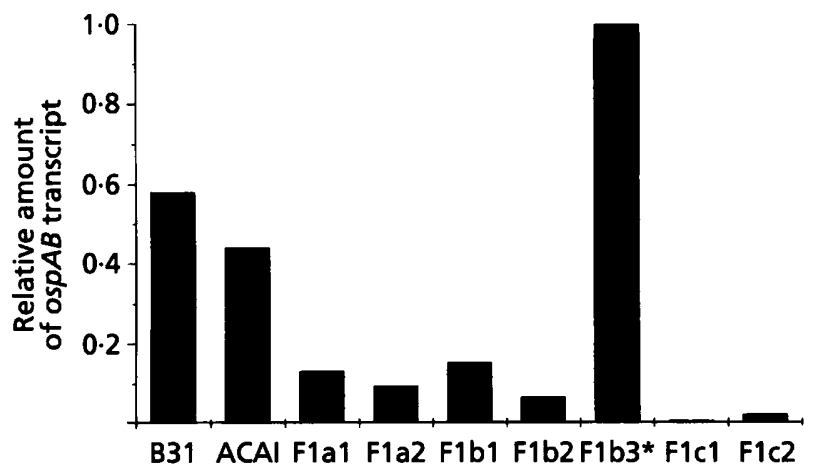

Fig. 7. The relative amount of $\operatorname{osp} A B$ transcript in $B$. burgdorferi B31, B. afzelii ACAl and different cultures of $B$. afzelii F1. F1b3* had been stored at $4{ }^{\circ} \mathrm{C}$ for a number of weeks before RNA preparation. The amount of transcript was measured by scanning Northern blots with a Phosphorlmager. To correct for different amounts of mRNA loaded in the lanes on the gel, the ospAB signals were first normalized to the amount of flagellin transcript in the preparation and then expressed relative to the highest value of ospAB.

performed (data not shown). The transcriptional start point of the osp $A B$ operon in $\mathrm{B} 31$ was previously determined to be at the $\mathrm{G}$ denoted +1 in Fig. 6. Primer extension analysis showed that the transcripts from both F1 and ACAI start at the same G nucleotide (data not shown).

The amount of $\operatorname{csp} A B$ transcript detected in different preparations of total RNA from strains ACAI and B31 was consistently very high. The amount of osp $A B \mathrm{mRNA}$ found in different cultures of F1 varies quite dramatically, as can be seen in Fig. 7. The highest amount of this transcript was found in culture F1b3 which had been stored at $4{ }^{\circ} \mathrm{C}$ for a number of weeks before the RNA was prepared. This suggests that the osp $A B$ transcript is probably very stable. It is also possible that the transcription of the $\operatorname{cs} p A B$ operon is induced or derepressed by either stationary phase growth or low temperatures.

The amount of $o s p C$ transcript was determined in B31, ACAI and the two F1 cultures expressing the lowest and highest amounts of osp $A B$ transcript, F1c1 and F1b3. As

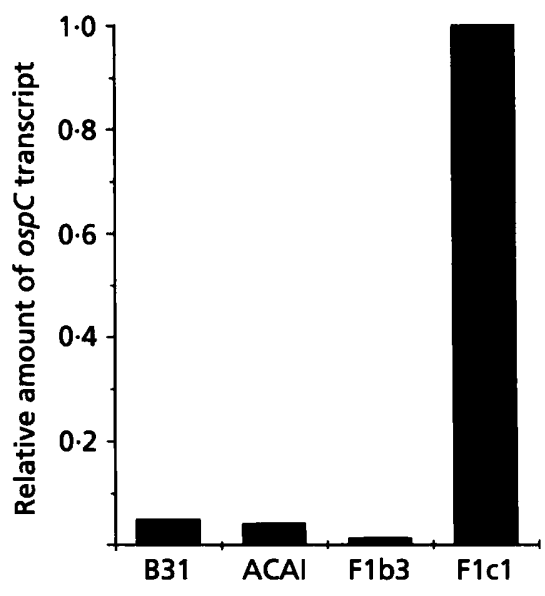

Fig. 8. The relative amount of ospC transcript from $B$. burgdorferi B31, B. afzelii ACAl and two different cultures of $B$. afzelii $\mathrm{F} 1$. The relative amounts of transcript were calculated as described in the legend to Fig. 7.

can be seen in Fig. 8, the F1c1 culture, which did not contain $\operatorname{cs} p A B$ transcript, expressed very high amounts of osp $C$ transcript, whereas $\mathrm{F} 1 \mathrm{~b} 3$, which contained the most osp $A B$ transcript, expressed the least ospC.

\section{Expression of OspA in E. coli}

To investigate the difference in expression of the OspA proteins from $B$. afzelii strains ACAI and F1 in further detail, the expression of the cloned $\operatorname{csp} A$ genes was studied in E. coli. The plasmid pMJ05 is a pUC18 derivative with a $5 \mathrm{~kb}$ EcoRI fragment which contains the whole osp operon from strain ACAI including a $1.5 \mathrm{~kb}$ upstream sequence. Plasmid pMJ06 is a subclone with a $1.5 \mathrm{~kb}$ HindIII fragment obtained from $\mathrm{pMJ} 05$ containing the osp $A$ gene cloned into pUC18 with a $0.5 \mathrm{~kb}$ upstream sequence. pMJ06 is a homologue of the pMJ08 clone which contains the $\mathrm{F} 1 \cos p A$ gene. The clones have the $\operatorname{osp} A$ gene in the same orientation opposite to the lac $Z$ promoter in pUC18. All os $p A$ expression should therefore be directed from its own promoter. Western blot analysis using the polyclonal anti-OspA serum shows that similar 


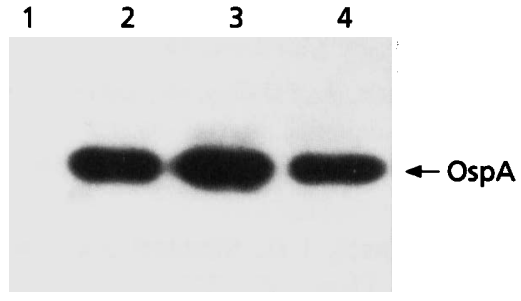

Fig. 9. Western blot analysis of lysates of E. coli DH5 $\alpha$ containing pUC18 (lane 1), pMJ05 (lane 2), pMJ06 (lane 3) and pMJ08 (lane 4) with polyclonal anti-OspA serum. The bound antibody was detected with the ECL Western blotting detection system.

expression levels were obtained from all three constructs (Fig. 9). The specificity of the signal is confirmed by its absence in the lane with pUC18 alone.

\section{DISCUSSION}

In the present study, we show that the expression of the outer surface proteins OspA, OspB and OspC differs considerably between the three Lyme disease Borrelia strains F1, ACAI and B31. This was shown previously by Barbour \& Schrumpf (1986). However, studies of the expression of the OspA proteins in E. coli showed that both the F1 and the ACAI osp $A$ genes can be transcribed and translated. This result indicates that there are factors in the Borrelia strains which modulate the expression of OspA which are not present in E. coli. Surrounding DNA seems to have little, if any, influence on expression, at least in E. coli, since no significant difference in expression between pMJ05 and pMJ06 can be seen. Nothing is known about DNA binding proteins and the effect of DNA topography on gene expression in B. burgdorferi sensu lato. Therefore, it remains possible that differences in the control region of the $\operatorname{cs} p A B$ operon are important for expression in the borreliae. To study whether differences in the turnover rate of the OspA proteins in ACAI and F1 could to some extent explain the various amounts of protein found, a pulse-chase experiment was performed (data not shown). This showed that the OspA proteins in both ACAI and F1 are extremely stable, with half-lives of more than one generation. Therefore, the differences in amounts of proteins are not due to variations in protein stability.

Eiffert et al. (1992) studied B. burgdorferi strain GÖ2 which expresses OspA, but not OspB. The lack of OspB expression was probably due to a point mutation, which introduced a stop codon into the beginning of the osp $B$ gene. Margolis \& Rosa (1993) recently published a study demonstrating that the expression of the OspA and OspB proteins are regulated at the transcriptional level. In that study, expression of the OspA and OspB protein genes was shown to be regulated by turning on and off the transcription of the whole $\operatorname{osp} A B$ operon. Padula et al. (1993) analysed the expression of the ospC gene and identified a region upstream of the promoter that affects the level of transcription of the ospC gene. $B$. burgdorferi B31 has a $51 \mathrm{bp}$ deletion in this control region which explains the lack of ospC expression in this strain. Collectively, these results suggest that Osp gene expression is essentially regulated at the transcriptional level.

Northern blot analysis with probes directed against either $\operatorname{osp} A$ or $\operatorname{csp} B$ gave the same result (data not shown), indicating that the osp $A B$ operons of both strains ACAI and $F 1$ are transcribed as one transcriptional unit as previously shown for the $B$. burgdorferi $\mathrm{B} 31$ osp $A B$ operon (Howe et al., 1985; Bergström et al., 1989). This is supported by the fact that the transcripts in all three strains are of the same molecular mass and have the same transcriptional start point. The amount of $\operatorname{csp} A B$ transcript found is consistently high in strains $\mathrm{B} 31$ and $\mathrm{ACAI}$, while it varies in different cultures of strain F1 (Fig. 8). This suggests that transcription is fully induced in B31 and ACAI, while it is only partially induced in F1. Alternatively, transcription in F1 is partially inhibited by some repressor which is inactive or absent in the other two strains. The translation of the $\operatorname{csp} A B$ operon also seems to be repressed to some extent in F1, as the relative amount of protein expressed is apparently low with respect to the amount of transcript produced. This is particularly true for $\mathrm{F} 1 \mathrm{~b} 2$, which has relatively high amounts of $\operatorname{cs} p A B$ transcript, but very low amounts of OspA and OspB proteins. Thus, this result is different from that previously shown by Margolis \& Rosa (1993) for the osp $A B$ operon of $B$. burgdorferi clone CA-11 $2 A$ from the tick isolate CA-11-90. In this clone no mRNA was detected, although the osp $A B$ operon was present and intact.

As Lyme disease Borrelia species move between ticks and mammals in their life cycle, they must be able to adapt to differences in their surroundings. Mammalian blood is very low in purines, while guanine is one of the primary waste products in ticks. The gua $A$ and gua $B$ genes are involved in purine biosynthesis, and are therefore very important for the borreliae when they are living in a mammalian host. Interestingly, the gua $A B$ operon has been mapped to the same $26 \mathrm{~kb}$ circular plasmid which encodes the ospC gene (Margolis et al., 1994). The two operons are separated by approximately $400 \mathrm{bp}$ and are transcribed in opposite directions. It can be speculated that activation of the gua $A B$ operon may simultaneously activate the ospC gene. It is also possible that activation of the $26 \mathrm{~kb}$ circular plasmid somehow represses the osp $A B$ operon resulting in the inverse relationship between OspAB and OspC expression observed in this study.

Our data demonstrate a new form of regulation of OspA and OspB proteins that has not been observed before. We suggest that expression of OspA and OspB can be regulated not only at the transcriptional level, but also at the level of translation. The factors involved in this regulation remain unknown and are currently under investigation. 


\section{ACKNOWLEDGEMENTS}

This work was supported by grants from the Swedish Research Council for Engineering Sciences (Dnr 92-695) and the Swedish Medical Research Council (Dnr 07922). Lenore Johansson is greatfully acknowledged for the electron microscopy work. We are indebted to Dr Amanda Cockshutt for carefully reading the manuscript. We are also thankful to Dr Göran Brattsand for technical advice.

\section{REFERENCES}

Åsbrink, E. \& Hovmark, A. (1985). Successful cultivation of spirochetes from skin lesions of patients with erythema chronicum migrans Afzelius and acrodermatitis chronica atrophicans. Acta Pathol Microbiol Immunol Scand Sect B Microbiol 93, 161-163.

Åsbrink, E., Hederstedt, B. \& Hovmark, A. (1984). The spirochetal etiology of erythema chronicum migrans Afzelius. Acta Dermatovenereol 64, 291-295.

Ausubel, F. M., Brent, R., Kingston, R. E., Moore, D. D., Seidman, J. G., Smith, J. A. \& Struhl, K. (1992). Current Protocols in Molecular Biology. New York: Greene Publishing Associates \& WileyInterscience.

Baranton, G., Postic, D., Saint Girons, I., Boerlin, P., Piffaretti, J.-C., Assous, M. \& Grimont, P. A. D. (1992). Delineation of Borrelia burgdorferi sensu stricto, Borrelia garinii sp. nov., and Group VS461 associated with Lyme borreliosis. Int J Syst Bacteriol 42, 378-383.

Barbour, A. G. (1984). Isolation and cultivation of Lyme disease spirochetes. Yale J Biol Med 57, 71-75.

Barbour, A. G. (1988). Plasmid analysis of Borrelia burgdorferi, the Lyme disease agent. J Clin Microbiol 26, 475-478.

Barbour, A. G. \& Garon, C. F. (1987). Linear plasmids of the bacterium Borrelia burgdorferi have covalently closed ends. Science 237, 409-411.

Barbour, A. G. \& Schrumpf, M. E. (1986). Polymorphism of major surface proteins of Borrelia burgdorferi. Zentralbl Bakteriol Parasitented Infektionskr $\mathrm{Hyg}$ Abt 1 Orig Reibe A 263, 83-91.

Barbour, A. G., Heiland, R. A. \& Howe, T. R. (1985). Heterogeneity of major proteins in Lyme disease borreliae: a molecular analysis of North American and European isolates. J Infect Dis 152, 478 484.

Barthold, S. W. (1993). Antigenic stability of Borrelia burgdorferi during chronic infections of immunocompetent mice. Infect Immun 61, 4955-4961.

Barthold, S. W. \& Bockenstedt, L. K. (1993). Passive immunizing activity of sera from mice infected with Borrelia burgdorferi. Infect Immun 61, 4696-4702.

Bergström, S., Bundoc, V. G. \& Barbour, A. G. (1989). Molecular analysis of linear plasmid-encoded major surface proteins, OspA and OspB, of the Lyme disease spirochete, Borrelia burgdorferi. Mol Microbiol 3, 479-486.

Bundoc, V. G. \& Barbour, A. G. (1989). Clonal polymorphism of outer membrane protein OspB of Borrelia burgdorferi. Infect Immun 57, 2733-2741.

Burgdorfer, W., Barbour, A. G., Hayes, S. F., Benach, J. L., Grunwaldt, E. \& Davis, J. P. (1992). Lyme disease: a tick borne spirochetosis? Science 216, 1317-1319.

Canica, M. M., Nato, F., du Merle, L., Mazie, J. C., Baranton, G. \& Postic, D. (1993). Monoclonal antibodies for identification of Borrelia afzelii sp. nov. associated with late cutaneous manifestations of Lyme borreliosis. Scand J Infect Dis 25, 441-448.

Craft, J. E., Fischer, D. K., Shimamoto, G. T. \& Steere, A. C. (1986).

Antigens of Borrelia burgdorferi recognized during Lyme disease.
Appearance of a new IgM response and expansion of the $\operatorname{IgG}$ response late in illness. $J$ Clin Invest 78, 934-939.

Eiffert, H., Ohlenbusch, A., Fehling, W., Lotter, H. \& Thomssen, R. (1992). Nucleotide sequence of the $\operatorname{osp} A B$ operon of a Borrelia burgdorferi strain expressing OspA but not OspB. Infect Immun 60, 1864-1868.

von Gabain, A., Belasco, J. G., Schottel, J. L., Chang, A. C. Y. \& Cohen, S. N. (1983). Decay of mRNA in Escherichia coli: investigation of the fate of specific segment of transcripts. Proc Natl Acad Sci US A 80, 653-657.

Harr, R., Făllman, P., Hăggström, M., Wahlström, L. \& Gustafsson, P. (1986). GENEUS, a computer system for DNA and protein sequence analysis containing an information retrieval system for the EMBL data library. Nucleic Acids Res 11, 273-284.

Hinnebusch, J. \& Barbour, A. G. (1992). Linear- and circularplasmid copy numbers in Borrelia burgdorferi. J Bacteriol 174, 5251-5257.

Howe, T. R., Mayer, L. W. \& Barbour, A. G. (1985). A single recombinant plasmid expressing two major outer surface proteins of the Lyme disease spirochete. Science 227, 645-646.

Howe, T. R., LaQuier, F. W. \& Barbour, A. G. (1986). Organization of genes encoding two outer membrane proteins of the Lyme disease agent within a single transcriptional unit. Infect Immun 54, 207-212.

Jiang, W., Luft, B. J., Munoz, P., Dattwyler, R. J. \& Gorevic, P. D. (1990). Cross-antigenicity between the major surface proteins (OspA and OspB) and other proteins of Borrelia burgdorferi. $J$ Immunol 144, 284-289.

Jonsson, M., Noppa, L., Barbour, A. G. \& Bergstrom, S. (1992). Heterogeneity of outer surface membrane proteins in Borrelia burgdorferi: comparison of the osp operons of three isolates of different geographic origins. Infect Immun 60, 1845-1853.

Jonsson, M., Elmros, T. \& Bergström, S. (1995). Subcutaneous implanted chambers in different mouse strains as an animal model to study genetic stability during infection with Lyme disease Borrelia. Microb Pathog (in press).

Marconi, R. T., Samuels, D. S. \& Garon, C. F. (1993). Transcriptional analyses and mapping of the ospC gene in Lyme disease spirochetes. J Bacteriol 175, 926-932.

Marconi, R. T., Samuels, D. S., Landry, R. K. \& Garon, C. F. (1994). Analysis of the distribution and molecular heterogeneity of the ospD gene among the Lyme disease spirochetes: evidence for lateral gene exchange. J Bacteriol 176, 4572-4582.

Margolis, N. \& Rosa, P. A. (1993). Regulation of expression of major outer surface proteins in Borrelia burgdorferi. Infect Immun 61, 2207-2210.

Margolis, N., Hogan, D., Tilly, K. \& Rosa, P. A. (1994). Plasmid location of Borrelia purine biosynthesis gene homologs. J Bacteriol 176, 6427-6432.

Norris, S. J., Carter, C. J., Howell, J. K. \& Barbour, A. G. (1992). Low-passage-associated proteins of Borrelia burgdorferi B31 : characterization and molecular cloning of OspD, a surface-exposed, plasmid-encoded lipoprotein. Infect Immun 60, 4662-4672.

Padula, S. J., Sampieri, A., Dias, F., Szcepanski, A. \& Ryan, R. W. (1993). Molecular characterization and expression of p23 (OspC) from a North American strain of Borrelia burgdorferi. Infect Immun 61, 5097-5105.

Rosa, P. A., Schwan, T. \& Hogan, D. (1992). Recombination between genes encoding major outer surface proteins $A$ and $B$ of Borrelia burgdorferi. Mol Microbiol 6, 3031-3040. 
Sadziene, A., Wilske, B., Ferdows, M. S. \& Barbour, A. G. (1993). The cryptic ospC gene of Borrelia burgdorferi B31 is located on a circular plasmid. Infect Immun 61, 2192-2195.

Sambrook, J., Fritsch, E. F. \& Maniatis, T. (1989). Molecular Cloning: a Laboratory Manual, 2nd edn. Cold Spring Harbor, NY: Cold Spring Harbor Laboratory.

Sanger, F., Nicklen, S. \& Coulson, A. R. (1977). DNA sequencing with chain-terminating inhibitors. Proc Natl Acad Sci USA 74, 5463-5467.

Shoberg, R. J., Jonsson, M., Sadziene, A., Bergström, S. \& Thomas, D. D. (1994). Identification of a highly cross-reactive outer surface protein (Osp) B epitope among diverse geographic isolates of Borrelia spp. causing Lyme disease. J Clin Microbiol 32, 489-500.

Wilske, B., Preac-Mursic, V. Schierz, G. \& Busch K. V. (1986). Immunochemical and immunological analysis of European Borrelia burgdorferi strains. Zentralbl Bakteriol Mikrobiol Hyg Ser A 263, 92-102.
Wilske, B., Preac-Mursic, V., Schierz, G., Gueye, W., Herzer, P. \& Weber, K. (1988a). Immunochemical analysis of the immune response in late manifestations of Lyme borreliosis. Zentralbl Bakteriol Mikrobiol Hyg Ser A 267, 549-558.

Wilske, B., Preac-Mursic, V., Schierz, G., Kuhbeck, R., Barbour, A. G. \& Kramer, M. (1988b). Antigenic variability of Borrelia burgdorferi. Ann NY Acad Sci 539, 126-143.

Wilske, B., Preac-Mursic, V., Jauris, S., Hofmann, A., Pradel, I., Soutschek, E., Schwab, E., Will, G. \& Wanner, G. (1993). Immunological and molecular polymorphisms of OspC, an immunodominant major outer surface protein of Borrelia burgdorferi. Infect Immun 61, 2182-2191.

Received 31 October 1994; revised 11 January 1995; accepted 3 February 1995. 